\title{
Inflammatory Leiomyosarcoma
}

National Cancer Institute

\section{Source}

National Cancer Institute. Inflammatory Leiomyosarcoma. NCI Thesaurus. Code C27495.

A morphologic variant of leiomyosarcoma characterized by the presence of an inflammatory infiltrate admixed with malignant spindle cells. 